\title{
DEVELOPMENT OF THE FUTURE TRANSLATORS' PROFESSIONAL COMPETENCY IN BILATERAL INTERPRETING: MODERN METHODS
}

\author{
Alla Bogush ${ }^{1}$, Tetiana Korolova ${ }^{2}$, Oleksandra Popova $^{3}$
}

\author{
State institution "South Ukrainian National Pedagogical University named after K. D. Ushynsky", \\ Odesa, Ukraine \\ ${ }^{1}$ svrada@i.ua, ${ }^{2}$ kortami863@gmail.com, ${ }^{3}$ Alex-Popova@ukr.net
}

\begin{abstract}
The paper presents the research on the effectiveness of the future translator and / or interpreter training using modern methods which facilitate the development of their professional competency in bilateral interpreting. The authors analyse psychological and pedagogical experience, modern educational technologies and prospects for future professionals in the context of bilateral interpreting. The scholars substantiate the results of the initiated phonetic research (including linguistic and translation analysis of audio texts) related to the semantics of prosodic means, which constituted the basis for the experimental study. The research reveals the outcomes of the experimental study conducted at Ushynsky University involving the third-year students who major in the English $\leftrightarrow$ Ukrainian translation. The four stages of the designated pedagogical experiment are specified: 1) pre-testing; 2) preparatory training course according to combined (interactive and traditional) authors' teaching methods; 3) after-testing; 4) assessment of the students' outcomes. The use of the experimental construct turns out to be practical due to these methods: cooperative learning, inquiry-based instructions, differentiation, professional development, technology and problem solving. The study also confirms the fact that the integration of traditional and modern technologies in teaching students to interpret information taking into consideration phonetic features of Ukrainian and English oral texts can help future translators develop their analytical and critical thinking, flexibility, agility and adaptability, initiative and entrepreneurialism while receiving, analysing and interpreting information. The detailed analysis of modern scientific literature proves that the use of the competence-oriented and context-centred approaches to the educational process contributes to the students' academic success.
\end{abstract}

Keywords: innovative professional training; professional competence; translators of English; interpretation; methodological support; indicators; semantics of prosodic means; prosody functions interaction.

\section{Introduction}

Interpreting occupies a leading position in the training system aimed at the future translators of any language nowadays due to the rapid integration of Ukraine into the European Union. Oral communication saves time for writing official letters, information leaflets, notifications, which enables negotiating parties to constructively collaborate in diverse spheres: political, economic, cultural, scientific, educational, etc. Interpreters are meant to be mediators in this significant activity both at the state level and at the level of inter-state cooperation. Interpreters who are specially trained in the field of interpretation are supposed to perform their professional duties qualitatively.

The key prerequisites for students' academic success in interpreting are stipulated by the properly organised educational process according to the specificities of each above-mentioned type of translation/interpretation. Therefore, theoretical research and practical verification of efficient pedagogical means, forms and methods facilitating the formation of the future translators' professional competence within the system of university training confirm the urgent demand for the determination and grounding of a corresponding set of curricular and/or extra-curricular constituents of their professional speech training.

The study of prosody in the field of interpretation seems to be fundamental for further elaboration of assignments for future interpreters. We agree with Ahrens (2005) that prosody, as an integral part of orally produced texts, "is used: 1) to structure the acoustic continuum uttered by a speaker; 2) to give prominence to those parts of the spoken text that the speaker considers to be important" (p. 1). Thus, the integration of phonetic studies and elaboration of the corresponding methodological support are proved to be expedient in the sphere related to the decoding and interpreting of information.

It should be also noted that while interpreting, a translator/interpreter is to keep to moral principles of oral communication: an interpreter is to keep to ethics of oral communication, to respect freedom of a client without restricting his/her dignity. An interpreter (while performing consecutive interpretation within international contacts, at the diplomatic level, to be more precise) is to fulfil diplomatic powers: he/she has no right to break the accuracy of the original content in order to maintain a diplomatic relationship as well as to prevent misunderstandings and conflicts. At the same time, an interpreter has no right to interfere with parties' relations or express his/her viewpoints concerning the original text. Which is more important, an interpreter has no right to react to communicant's emotional attitudes or 
individual defects, though he/she should neutralise (defects) and transform them into the target text in compliance with the literary norms of the target language, etc.) (Popova, 2017).

No doubt, interpreter's behaviour is to meet the noted requirements but one cannot deny the significance of intonation used in the process of interpreting. Linguists acknowledge that the wrong use of intonation, even if combined with the appropriate use of lexical units, might lead to misunderstanding. Furthermore, the "interpretation imbalance", aroused because of the wrong oral perception of intonation models and failure to transfer information from one language into the other one, causes deviations in the development of students-interpreters' switching skills. As far as the switching skills are concerned, we affirm our full acceptance of Zinukova's (2018) research in which the author proves that the formation and automation of the switching skills of students-interpreters will help optimise and speed up the professional development of future interpreters. Zinukova (2018) also notes that interpreters should "consider the development of switching skills as one of their main tasks" (p. 174). We support the ideas of Trotsko (2018) and Korotkova (2018) regarding students' immersion into native speakers' environment and demonstration of how a foreign language is used in real communicative situations. Therefore, it seems essential to organise purposeful practice for students in bilateral interpreting, to teach them to identify interlocutor's emotional attitude and to react in an adequate way.

Students' academic success, while being trained in English-Ukrainian translation/interpretation, much depends on their language awareness, which is to be fostered. Therefore, we might assume that teaching (future translators) English plays a significant role in their professional training. Teaching tools used skillfully by university instructors facilitate students' development in terms of their proficiency. We share the ideas announced by Tarnopolsky (2018) that the fostering of students' language awareness can be motivated and developed by the way of activating intuitive heuristics and doing creative tasks that are heuristics-oriented; besides we are to take into consideration the fact that learning involves not only mostly intuitive and subconscious target language acquisition but also acquisition of the content of majoring disciplines and target culture (pp.5-11). The scientist also highlights the importance of experiential-interactive learning activities which always integrate language skills.

We do acknowledge that while training future translators/interpreters it is necessary to give students complex communicative assignments as well as exercises connected with language use: learning projects which presuppose brainstorming and discussions (speaking and listening), collecting written and oral information through reading and listening, completing the project tasks in oral (speaking and listening) and written forms (writing), etc. The designated communicative language activities (speaking, listening, reading and writing) are meant to form the basis for students' training both in spoken interpretation and in written translation. It should be mentioned that these are (spoken) interpretation and written translation that are of great importance in the educational context according to the updated descriptors of the Common European Framework of Reference for Languages (Brian North, 2016). On the other hand, social and cultural educational components within the system of teaching English (or other foreign languages) constitute students' overall proficiency in English alongside with linguistic competences (lexical, phonological, syntactical knowledge and skills). Modern education conditions and technologies enable educators to organise language activities, involving reception, production, interaction or mediation (in particular interpreting or translating). Each of these types of activity is possible in relation to texts in oral or written form, or both (North, 2016).

It is expedient to mark that nowadays the competence-oriented approach is one of the methodological determinants in teaching languages. Scott (2016) highlighted its importance when presenting UNESCO Working Papers. She refers to Wagner (2010) and the Change Leadership Group at Harvard University who identify "a set of competencies and skills that students need to be prepared for twenty-first century life work and citizenship" (p.4). They also distinguish these personal qualities and abilities: critical thinking and problem solving, agility and adaptability, initiative and entrepreneurialism, effective oral and written communication, accessing and analysing information (Scott, 2016). We should note that when training future translators/interpreters, university teachers are to develop students' communicative and speaking competence which is defined by Korniyaka (2018) as "a complex, intra-contradictory combination of communicative and speech knowledge and skills, reflecting the goals and results of the communicative and speaking activities performed by the subject" (p. 189).

Solving the problem arising due to differences between demands of different spheres for specialist's profile (a set of professional competences) and curriculum objectives of tertiary schools where future specialists are trained can contribute to Ukraine's development as an advanced country. 
The above-mentioned problem predetermines the primary aim of the article - to represent an experimental training aimed at the English-language translators in the field of the English $\leftrightarrow$ Ukrainian interpretation in compliance with modern European standards and needs. The solution of the objectives facilitates achieving the stated aim: 1) to study prosodic means as the criteria determinants facilitating the development of the future English-language translators' professional competence; 2) to substantiate the elaborated criteria and indicators within the experimental training of the future translators in the field of bilateral interpretation.

In the view of the stated objectives, we can formulate the conceptual hypotheses: the students' academic success depends upon their linguistic knowledge and skills integrated with the appropriate methodological support; students' involvement into profession-focused phonetic studies/research should precede their training in bilateral consecutive interpreting.

\section{Methods}

\section{Participants}

Human experts (two non-native speakers and four native speakers of English) carried out acousticperceptual speech analysis of prosodic means for educational purposes.

30 third-year students majoring in the English $\leftrightarrow$ Ukrainian translation were involved into the pedagogical experiment (South Ukrainian National Pedagogical University named after K. D. Ushynsky) which covered 2016-2017 and 2017-2018 academic years. The participants were divided into experimental (EG) and control (KG) groups, 15 students in each.

\section{Apparatus and materials}

We used both theoretical and practical analyses of psychological and pedagogical experience in the viewpoint of the research in order to substantiate the scientific and methodology support which could help to form professional competency of the future translators of English in the field of interpretation.

The framework of the research also presupposed the use of empirical and theoretical methods. The experimental phonetic research made it possible to reveal the mechanisms of prosodic models correlation with various spheres of speech semantics. The linguistic and translation analysis of different audio texts enabled the assessment of the students' deep/superficial understanding of the original texts, the communicative function of utterances and translation/interpretation strategy/tactics, students' skills/abilities to use adequate translation means. The quantitative analysis facilitated establishing an appropriate ratio of the outcomes within the pre-experimental and post-experimental stages of the above-mentioned training.

\section{Procedure}

The pedagogical experiment consisted of four stages: 1) pre-testing of the students (in order to determine the level of their basic knowledge and skills in oral translation; 2) preparatory training course intended for the future translators of English according to combined (interactive and traditional) authors' teaching methods; 3 ) after-testing; 4) assessment of the students' outcomes. The integrity of the assessment process was provided by these control methods:

- testing on theoretical issues regarding semantics of prosodic means in English and Ukrainian, distinctive features in intonation of the two languages under analysis, the mechanisms of prosodic models correlation with various spheres of speech semantics, prosody functions interaction;

- analytical and practical tasks aimed at determining the formation level of the students' phonological knowledge, skills and abilities;

- practicing in sight translation and consecutive interpretation.

While elaborating final (post-experimental) testing, we took into account the typology of mistakes made at the before-experimental stage in order to observe the quality of the students' speech. The knowledge and skills obtained by the future translators after the preparatory training course constituted the professional competency of the future English-language translators in the field of interpretation (criterion) represented by phonological, audial, oral and transfer indicators. The specification of these indicators is given in Appendix 3.

\section{Results}

The linguodidactic experience stipulated the necessity to initiate acoustic-perceptual speech analysis of prosodic means for educational purposes. Although the acoustic-perceptual method is often 
criticised because of its subjectivity, it was primarily chosen because firstly, the goal was to understand the semantics of prosodic means in the complex linguistic context; secondly, we confirm the fact that the human ear can grasp nuances that would be ignored by the software.

The results of the initiated phonetic study contributed to the elaboration of corresponding assignments and teaching tools. The relevance of the study is grounded on the assumption that prosodic elements are significant clues for the listener when processing spoken input. In the presented research, a systemic analysis of some problems related to the semantics of prosodic means is made. This problem causes much difficulty since either of the aspects mentioned above (semantics characterised by its poly-significance and tight connection with many linguistic categories, on the one hand, and prosody with its multiple functions and low degree of formalisation as to semantics, on the other one) presents a very complicated system. It should be mentioned that the interaction of these two factors makes the research much more difficult.

Modification of intonation in conveying various semantics differs greatly in the two languages under analysis: English and Ukrainian. This phenomenon is distinctly seen in intonation specificity of different communicative types of sentences. Thus, the Ukrainian speaker's speech should not imitate the alteration of Ukrainian melody, loudness and tempo characteristics when speaking English. Such a misusage of intonation will lead to misunderstanding turning a question into a statement, a request into an order, a greeting into parting and so on. According to the original investigation of the authors, it can be stated that the intonation of a communicative type of a sentence is closely connected with the attitudinal meaning expressed by the speaker in a speech act. For example, doubt accompanied by a fall-rise in an English statement will take a rise in Ukrainian; a fall-rise in Ukrainian turns an English statement conveying the attitude of doubt into a question.

Therefore, when training Ukrainians to speak English, one should pay special attention to distinctive features in intonation of the two languages under analysis. Semantic adequacy (conceptual fidelity) is of primary importance for a person learning a foreign language; in this connection, one should remember prosodic distinctions in the contacting languages that is one of the most important factors for semantic integrity of the utterances. The fact that semantics of intonation can cause misunderstanding makes intonation a strong point that needs a close examination.

The experimental phonetic research carried out made it possible to reveal the mechanisms of prosodic models correlation with various spheres of speech semantics. The key points are as follows: (1) most communicative types of sentences demonstrate interaction with the prosodic markers of attitudes that correlate semantically with a certain communicative type; (2) attitudes are divided into two classes which differ according to presence /absence of prosodic constructions of "their own"; (3) prosodic actualisation of attitudinal complexes.

As to the issue of prosodic correlates of attitudes (2), it is to be stated that the attitudes aimed at expressing definite attitudinal and emotional state are included in the first group. These attitudes possessing the prosodic correlates form the invariant basis of attitudinal prosodic models. The other group comprises the attitudes that exploit the prosodic models of the first one.

The correlation mechanisms between prosody and communicative types are regarded as the invariant fundamentals of prosody patterns semantics. The patterns variety can be caused by a number of factors: polysemy of either prosodic pattern and their synonymy. Prosody polysemy is actualised in two ways meaning and function. The first one is connected with such universal phenomena as homonymy, hyponymy, meaning transfer. Polyfunctionality is reflected in prosodic functions mutual interaction (attitudinal, logical, semantic, communicative, syntagmatic delimitation, syntagmatic unification).

The analysis of the correlation between the prosodic means and semiological units is complicated by the fact that in a communicative process various complexes of attitudes are simultaneously expressed (3). The examination of English and Ukrainian speech demonstrated the reliable data of attitudinal complexes acoustic correlates being recurrent, their degree of stability and the importance of prosody components while expressing attitudinal complexes. The most interesting are the following conclusions: the state of prosody markers stability depends on the place the attitudinal component occupies in the semantic field hierarchy the prosody of the initial elements dominates in a complex of attitudes.

Alongside with the above-mentioned reasons of polysemy in prosody semantics interpretation is the fact of prosody interaction with non-prosodic means. The structure of the latter is homogeneous with prosody (in origin) in the way of expression but heterogeneous with respect to prosody as to the meaning (and functions).

The research resulted in the statement that the mechanism responsible for the final prosody contour is not unique and depends on a number of factors:

- presence/absence of prosodic models "of their own" in attitudinal meanings;

- stability degree of correlation between these models and semantics; 
- degree of semantic character intensity actualised by a prosodic model;

- degree of the initial prosody structures resemblance;

- degree of the combined functions, language nature sameness.

Depending on these factors prosody functions interaction exists in the form of neutralisation, domination, equality and subordination.

In spite of some specific prosodic characteristics in either of the two languages where prosody fulfils several functions simultaneously, the character of "prosody-semantics" correlation in both languages is the same. The most important features of this mechanism can be qualified as language universals. The analysis of functional and semantic factors influencing the prosody models degree of stability demonstrates the different potential of prosody functions effect. Most stable are prosody patterns responsible for attitudinal and emotive functions. The status of other functions changes from a subordinating (syntagmatic delimitation) to the dominating one (emotional state of the speaker). Therefore, generalising prosody contour as a polysemantic phenomenon preserves the relevant prosodic characters of the dominating function.

The obtained results constituted the basis for the initiated experimental training. To our regret, there has not been found out any scientific issues on the peculiarities of the English translators'/interpreters' professional training in the sphere of prosodic means decoding within the modes of neutralisation, domination, equality and subordination. Thus, we intend to specify the contents of the teaching/learning process aimed at the would-be translators of English in the sphere of interpretation.

The academic success turned out to be stipulated by the use of the competence-oriented and contextcentred approaches to the educational process and combination of traditional (lectures, practical classes and seminars) and new interactive methods/forms of teaching/learning: interactive lectures; interactive business/role-playing games; interactive workshops, seminars - panel discussions involving native speakers. Examples of the experimental tasks are included in Appendix 1 and Appendix 2.

It should be mentioned that the elaborated system of the curricular and extra-curricular activities could be also applied when training students in translating/interpreting texts in these language pairs: Chinese $\leftrightarrow$ Ukrainian and English $\leftrightarrow$ Chinese.

The results of the data processing presented in Diagram 1 showed the dynamics of the proficiency levels demonstrated by the future English-language translators within their professional competency in the field of interpretation.

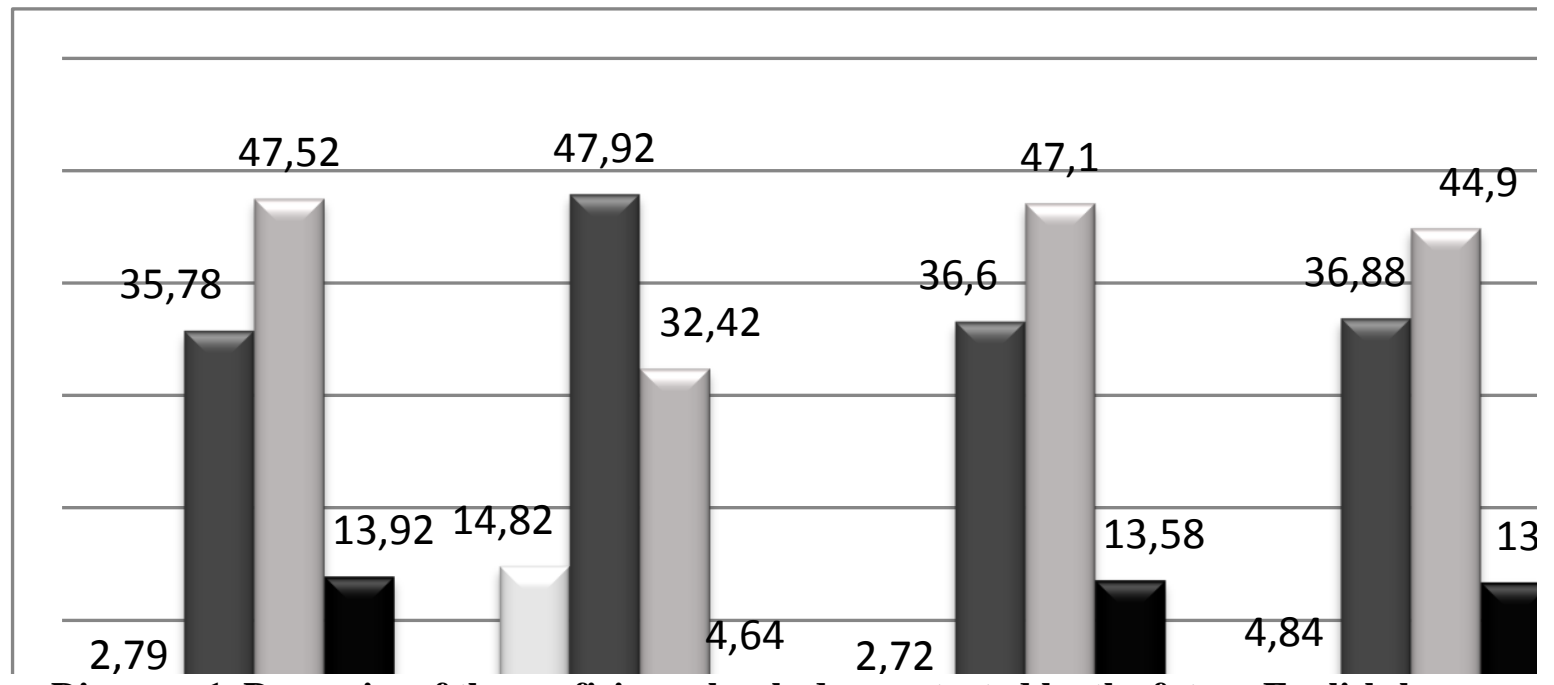

Diagram 1. Dynamics of the proficiency levels demonstrated by the future English-language translators within the professional competency in interpretation (\%)

The students were assessed in compliance with the four-level evaluation system: the high level ( 90 100 scores), the sufficient level ( $74-89$ scores), the intermediate/satisfactory level ( $60-73$ scores), the low level (0 - 59 scores) (Popova, 2017).

Thus, according to the results of the final testing/after-testing (see Diagram 1), 14,82\% of the EG students reached the high level (2,79\% prior to the experimental training course), $47,92 \%$ of the EG students showed the sufficient level (35,78\% prior to the experimental training course), 32,42\% of the EG students got the intermediate (satisfactory) level (47,52\% prior to the experimental training course), $4,64 \%$ of the EG students demonstrated the low level (13,92\% prior to the experimental training course). The KG had the following results: the high level $-4,84 \%$ (prior data $-2,72 \%$ ), the sufficient level - 
$36,88 \%$ (prior data $-36,6 \%$ ), the satisfactory level $-44,9 \%$ (prior data $-47,1 \%$ ), the low level $-13,38 \%$ (prior data $-13,58 \%$ ).

Let us consider the components of the professional competency in interpretation acquired by the experiment participators (See Table 1 and Diagram 1).

Comparative data demonstrating the levels of the professional competency in interpretation achieved by the future English-language translators according to the results of the control testing (\%)

\begin{tabular}{|c|c|c|c|c|c|c|}
\hline 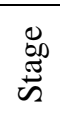 & 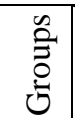 & Indicators & high & sufficient & $\begin{array}{l}\text { intermediate } \\
\text { (satisfactory) }\end{array}$ & low \\
\hline 1 & 2 & 3 & 4 & 5 & 6 & 7 \\
\hline \multirow{8}{*}{ 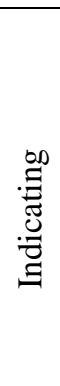 } & \multirow{3}{*}{ EG } & Phonological & 5,05 & 40,16 & 45,69 & 9,1 \\
\hline & & Audial & 0 & 30,39 & 50,32 & 19,29 \\
\hline & & Oral transfer indicator & 3,31 & 36,79 & 46,54 & 13,36 \\
\hline & \multirow{4}{*}{ KG } & Total $(E G)$ & 2,79 & 35,78 & 47,52 & 13,92 \\
\hline & & Phonological & 4,84 & 41,53 & 44,63 & 9,0 \\
\hline & & Audial & 0 & 30,9 & 50,1 & 19,0 \\
\hline & & Oral transfer indicator & 3,33 & 37,35 & 46,57 & 12,75 \\
\hline & & Total $(K G)$ & 2,72 & 36,6 & 47,1 & 13,58 \\
\hline \multirow{10}{*}{$\underset{\text { 可 }}{\bar{F}}$} & \multirow[t]{3}{*}{ EG } & Phonological & 18,9 & 54,66 & 22,83 & 3,01 \\
\hline & & Audial & 12,15 & 41,58 & 38,44 & 7,83 \\
\hline & & Aural transfer indicator & 13,4 & 47,51 & 35,99 & 3,1 \\
\hline & & Total $(E G)$ & 14,82 & 47,92 & 32,42 & 4,64 \\
\hline & & DIFFERENCE & $+11,43$ & $+12,14$ & $-15,1$ & $-9,28$ \\
\hline & $\mathrm{KG}$ & Phonological & 11,1 & 43,38 & 39,11 & 6,41 \\
\hline & & Audial & 0 & 30,85 & 48,28 & 20,87 \\
\hline & & Oral transfer indicator & 3,42 & 36,4 & 47,32 & 12,86 \\
\hline & & Total $(K G)$ & 4,84 & 36,88 & 44,9 & 13,38 \\
\hline & & DIFFERENCE & $+2,12$ & $+0,28$ & $-2,2$ & $-0,2$ \\
\hline
\end{tabular}

The improvement of the EG students' professional competency in interpretation can be explained by a systemic stage-by-stage methodical system combined with their positive motivation to participate in educational process in close collaboration with university instructors (integrative character of disciplines, contrastive analysis of linguistic units representing different levels), whereas the KG students' academic activities proved to be of a linear character without taking into account the significance of studying languages through the prism of contrasting analysis of linguistic units at every level.

According to the phonological indicator, $18,9 \%$ of the EG students achieved the high level $(5,05 \%$ prior to the experimental training course), $54,66 \%$ of the EG students demonstrated the sufficient level $(40,16 \%$ prior to the experimental training course); $22,83 \%$ of the EG students had the satisfactory level $(45,69 \%$ prior to the experimental training course); $3,01 \%$ of the EG students $(9,1 \%$ prior to the experimental training course) were at the low level.

The future translators/interpreters demonstrated good theoretical knowledge of the standard and emotional-attitudinal English and Ukrainian intonation within diverse discourses: they clarified the semantics of accentuation and terminal tones depending on communicative types of sentences, deciphered prosody patterns responsible for attitudinal and emotive functions; pronounced, transcribed and intoned English / Ukrainian segmental and suprasegmental units in various prosodic modes. Their English speech continuum sounded natural. Due to appropriate training, the future translators/interpreters did not allow interference of native language intonation models/patterns with foreign speech. They demonstrated the practical knowledge of the phonetic rules concerning assimilation, accommodation, reduction, devoicing/voicing of consonants, etc., which helped the students to avoid false pronunciation of certain words in speech continuum.

According to the audial indicator, $12,15 \%$ of the EG students achieved the high level (it had not been detected at the previous stage); the satisfactory level was demonstrated by $41,58 \%$ of the EG students $(30,39 \%$ prior to the experimental training); $38,44 \%$ of the students showed the satisfactory level $(50,32 \%$ 
prior to the experimental training); $7,83 \%$ of the EG students had the low level $(19,29 \%$ prior to the experimental training).

Since the experimental conference discourse was diversified by the audio recordings of reports devoted to some issues on Philology, Pedagogy/Psychology, Philosophy and Culture Studies, the future translators did their best not only to perceive audio information, but to render it into the target language taking into consideration the semantics of prosodic means as well.

As for the listening of telephone conversations in English and Ukrainian, the EG students without any complications decoded the intonation patterns of the heard speech, perceived the general meaning, despite natural and technical jamming, planned and performed necessary speech actions correctly in the English and Ukrainian languages.

The experimental results of the KG students according to the audial indicator turned out to be similar with the pre-experimental ones: none of the KG students demonstrated the high level; the sufficient and satisfactory levels decreased by $0,05 \%$ and $1,82 \%$ (total $1,87 \%$ ); whereas the low level increased by $1,87 \%$. The results of the final test testified the lack of the KG students' attention to the analysis of the prosody functions interaction (neutralisation, domination, equality and subordination); ignorance of the distinctive features in intonation of the two languages under analysis, which provoked the incorrectness of communicative behaviour in the course of performing further speech exercises.

According to the oral transfer indicator, within the tasks for consecutive interpretation, the high level in the EG increased by 10,09\% compared with the KG (0,09\% respectively). The KG students, as previously, demonstrated generally the satisfactory level $(47,32 \%)$. The number of the KG students who achieved only the low level exceeds many times the low EG results: $12,86 \%(\mathrm{KG}), 3,1 \%(\mathrm{EG})$. Some slight differences in the results of the KG students' control works (from $-0,95$ to $+0,75$ ) could be explained by the lack of exercises for bilateral consecutive interpretation involving decoding analysis of the correlation mechanisms between prosody and communicative types within the languages under study against the background of lexical, grammatical and stylistic phenomena. However, the differences in the successfulness of the proposed tasks fulfilled by the KG and EG students are significant.

The EG students perceived the structural scheme of the substantive and semantic implication of the English and Ukrainian intonation in an inventive way and fixed it in memory; carried out multi-level text analysis and compression, including interpreter's notes (with subsequent decoding and interpreting). An increase in the EG students' academic success can be explained by effective innovative methodology support which facilitated the EG students' learning to identify and understand the denotative and connotative semantics of intonation within the English and Ukrainian languages as well as to accommodate it while interpreting texts from English into Ukrainian and from Ukrainian into English. We can observe the development of the students' basic knowledge and awareness, skills and abilities within their competency in bilateral interpretation after the experimental course of study. See below.

\section{Basic knowledge and awareness:}

- knowledge of the segmental (the sound system, types of stress, minimal phonetic units, structure and types of syllables, use of terminal tones) and suprasegmental (actual segmentation of speech continuum; semantics of prosodic means, mechanisms of prosodic models correlation with various spheres of speech semantics, prosody functions interaction; spelling, pronunciation, transcription and intoning rules) levels in terms of standard and attitudinal use of phonetic units within the English and Ukrainian languages;

- awareness of psycholinguistic regularities of generation and oral perception of information/discourse as well as psycholinguistic features of the process of interpretation (consecutive interpretation, sight interpretation).

\section{Basic professional skills and abilities:}

- to correctly perceive, pronounce and record in graphic form (transcribe) separate sounds, words, phrases and sentences in English and Ukrainian, depending on these factors: presence/absence of prosodic models "of their own" in attitudinal meanings; stability degree of correlation between these models and semantics; degree of semantic character intensity actualised by a prosodic model; degree of the initial prosody structures resemblance; degree of the combined functions language nature sameness;

- to understand the main idea, the general content and details of the multi-genre material perceived by the hearing (debates, official reports, discussions, (non) official negotiations, telephone conversations, radio and TV programs, etc.), the communicative intention of the interlocutor (regardless of his / her age, social status, gender) accommodating prosody functions interaction which exist in the form of neutralisation, domination, equality and subordination (despite possible natural and technical obstacles - noises, disconnection, etc.); 
- to keep perceptual information in the RAM (random access memory);

- to determine the semantic content of unfamiliar words and phrases according to the content and semantics of prosodic means; to use descriptive interpretation, in this regard;

- to synchronously perceive oral / audio information (communicative quanta, their character, means of their logical organisation, unfamiliar words and phrases) and orally reproduce the text in the target language for a limited time;

- to adequately perceive, decode the implicit content of the English and Ukrainian intonation against the background of other linguistic devices (lexical, grammatical, stylistic, etc.), fix the substantive and semantic content of the authentic / original message in the memory and reproduce it in the target language using adequate translation/ interpretation means alongside with the system of interpreter's notes (being aware of their decryption); to make compression and decompression of the text (consecutive interpretation).

\section{Discussion}

Interpreting is considered to be one of the most difficult activities connected with the perception and transfer of information. The designated type of translation constitutes the psycholinguistic classification alongside with these types: written-written, oral-oral, written-oral, oral-written.

It is expedient to remind that the students' academic success depends upon their linguistic knowledge and skills integrated with the appropriate methodological support. We can confirm that the conducted phonetic research contributed to their involvement in profession-focused activities connected with bilateral consecutive interpreting. Furthermore, thanks to the obtained results of the phonetic research, which preceded the experimental study, the students were able to indicate, decode and interpret the phonetic features determining the speakers' intention and attitude in an adequate way.

Taking into consideration the proposed methodological ground, "the competence-oriented approach to educating future specialists of different branches being the main one" (Bogush, 2009), we have elaborated some criteria for the future English-language translators' professional competence which comprised three particular competencies (criteria): the professional competency of the future English-language translators in the field of written translation; the professional competency of the future English-language translators in the field of interpretation; the professional competency of the future English-language translators in the field of written translation $\leftrightarrow$ interpretation. We understand the word "criterion" as a means of evaluation of activity outcomes, the content of which is disclosed due to certain markers (indicators). The suggested criteria are grounded on the type and mode of translation/interpretation, their revelation becomes possible if appropriate systems of exercises/assignments, methods and pedagogical conditions are applied. Knowledge/awareness and skills are the objects of competence development.

In our opinion, translator's/interpreter's professional competence comprises six constituents-subcompetencies: linguistic, sociocultural, communicative-speaking, discourse-oriented, specific translationtechnological and specific interpretation-technological. The linguistic, sociocultural and communicativespeaking competencies form the platform for further professional development, whereas technological skills aimed at using translator's/interpreter's professional tools (translation devices and models, computer-assisted translation (CAT) and editing software, etc.), taking into account particular features of a discourse where interpretation/translation "unfolds", are actualised in both translation and interpretation productivityefficiency. In this respect, we correlate the criteria-markers of the students' competence in the field of interpretation with the determined knowledge/awareness and skills. Since we devote our pedagogical research to the competency in the field of bilateral interpretation (as a component of translator's/interpreter's professional competence), we do acknowledge that we need to elaborate the appropriate methodology support for the development of their competency in (written) translation within their holistic professional training as future translators-interpreters who could productively function in the framework of international educational environment.

Let us turn back to the experimental study. It is believed that theoretical material is difficult to master, that is why we used some teaching strategies which facilitated its successful acquisition and practical use. Understanding that phonetic issues are rather complicated for mastering, we decided to apply the teaching methods which might combine students' self-guided work and interactive forms of their knowledge, awareness and skills representation. Cooperative learning helped to develop the students' abilities to work together in groups and to enhance critical thinking skills while mastering theoretical material regarding intonation modification (Lecture-workshop "Intonation modification: topical issues"). The inquiry-based instructions included thought-provoking questions related to mechanisms of prosodic models correlation with various spheres of speech semantics and inspired students to think for themselves within their professional sphere and become more independent learners (Lecture-polylogue "Mechanisms of prosodic 
models correlation with various spheres of speech semantics"). Differentiation techniques covered the students' independent work within the Lecture "Students' self-guided work" where the university instructor allocated tasks based on their abilities, on the one hand; and gave appropriate support to those who needed time and explanation for mastering some phonetic phenomena, on the other hand. The method of professional development manifested itself during the Seminar-panel discussion "Do it yourself". Some university professors were invited in order to comment on the students' academic success in "professional phonetics". Due to the well-organised mode of study, the students managed to elaborate recommendations concerning the mechanisms of prosodic models correlation with various spheres of speech semantics (English vs Ukrainian) and to represent them in groups. At the end of the seminar, the students got some useful advice from their teachers. Thereafter the students confirmed a set of universal recommendations for further use. By using this method, we succeeded in the creation of a dynamic and motivational environment for students. It should be noted that the designated teaching methods (techniques) were used as a complex during the experiment, each of them being applied in a certain degree. A series of interactive exercises ("Acting Art", "Guess who the politician is", "Phono-expert", "Translator-scientist", "How should one achieve success in business at the international level?") was fulfilled involving the methods of technology and problem-solving. These methods helped to actively engage the students. Digital media and mobile devices, such as iPads and tablets, contributed to better fulfilment of the assignments, as follows:

- to imitate phonetic phonopassages of certain audio / video pieces (Exercise "Acting Art");

- to intone certain utterances, to analyse the intonation semantics of the extracts under study and to read them according to the patterns (Exercise "Guess who the politician is");

- to represent phonetical reading of the proposed texts according to the forms of prosody functions interaction: neutralisation, domination, equality and subordination (a complex exercise "Phono-expert");

- to find out the interlocutors' communicative intention while listening to audio recording (in English and Ukrainian) of polylogues among conference participators and to continue the dialogue with the conference participator(s) (group mate(s)) in the language of the conference in compliance with the moral and ethical norms of the discourse (Exercise "Translator-scientist");

- to listen to authentic English / Ukrainian telephone conversations (containing obstacles), to detect the interlocutors' communicative intention and to interpret the "damaged" phone conversation (Exercise "How should one achieve success in business at the international level?"). Encouraging students to ask and answer questions, to investigate and verify their own ideas, to demonstrate the obtained knowledge and skills helped to improve their problem-solving skills.

Thus, the development of the future translators' professional competency in bilateral interpreting proved to be effective due to the appropriate methodology support (competence-oriented and context-centred approaches; a combination of traditional and new interactive methods/forms of teaching/learning).

\section{Conclusions}

In conclusion, we may assume that the initiated experiment proved to be efficient since it enabled the development of most future English-language translators'/interpreters' professional competency in the field of interpretation due to the appropriate methodology support.

The conducted experiment was based on the phonetic research which helped to reveal certain mechanisms of prosodic models correlation with various spheres of speech semantics: a) correlation mechanisms between prosody and communicative types of sentences; b) types of interaction of prosodic functions in the framework of their professional activity. These mechanisms constituted the basis for assignments and determined the choice of linguistic and pedagogical methods alongside with approaches within the realisation of the teaching/learning process.

The use of the competence-oriented and context-centred approaches to the educational process as well as a combination of traditional (lectures, practical classes and seminars) and new interactive methods/forms of teaching/learning: interactive lectures; interactive business/role-playing games; interactive workshops, seminars - panel discussions involving native speakers contributed to the students' academic success. The use of the experimental construct turns out to be practical due to these methods: cooperative learning, inquiry-based instructions, differentiation, professional development, technology and problem-solving. The effectiveness of the experimental training was proved in accordance with phonological, audial, oral and transfer indicators. Due to university instructors' teaching tools, it was possible to develop students' basic professional skills and abilities in the field of bilateral interpretation.

Through the entire experiment, the students were encouraged to participate actively both in curricular activities and in self-guided independent work, which also contributed to the development of their analytical 
and critical thinking, flexibility, agility and adaptability, initiative and entrepreneurialism while receiving and analysing the information as well as interpreting it.

Thus, the prospect of efficient translator training at tertiary schools is seen in elaborating methodological support aimed at teaching simultaneous interpretation and integrating it with the one aimed at teaching bilateral consecutive interpretation taking into account modern social and economic demands and the framework of academic mobility projects.

\section{References}

Ahrens, B. (2005). Analysing prosody in simultaneous interpreting: difficulties and possible solutions. The interpreters' Newsletter, 13, 1-14. Retrieved January 10, 2019, from http://hdl.handle.net/10077/2465

Bogush, A. M. (2009). Kompetentnisnyi pidkhid u pidhotovtsi maibutnikh fakhivtsiv doshkilnoi osvity u vyshchomu navchalnomu zakladi [Competence-oriented approach to the future preschool educator training at an institution of higher education]. In A. M. Bogush (Ed.), Realizatsiia yevropeiskoho dosvidu kompetentnisnoho pidkhodu u vyshchii shkoli Ukrainy: materialy metodolohichnoho seminaru [Realisation of the European experience of a competence-oriented approach at higher school of Ukraine: materials of the methodological seminar] (pp. 271-287). Kyiv, Ukraine:Pedahohichna dumka.

Brian North, E. P. (2016). Common European Framework of Reference for Languages: Learning, Teaching, Assessment Developing Illustrative Descriptors of Aspects of Mediation for the CEFR. Retrieved January 16, 2019, from https://rm.coe.int/common-european-framework-of-reference-for-languages-learning-teaching/168073ff31

Brovchenko, T. O. \& Korolova, T. M. (2006). English Phonetics (Contrastive analysis of English and Ukrainian pronunciation). Mykolaiv, Ukraine:Vyd-vo MDHU im. Petra Mohyly.

Korniyaka, O. (2018). Features of University Teachers' Communicative-Speaking Competence. Psycholinguistics, 24(1), $183-206$. https://doi.org/10.31470/2309-1797-2018-24-1-183-206

Popova, O. V. (2017). Profesiino-movlennieva pidhotovka maibutnikh perekladachiv kytaiskoi movy v umovakh universytetskoi osvity [Professional speech training aimed at the future Chinese-language translators under conditions of university education]. Doctoral dissertation, Odesa, Ukraine.

Popova, O., Yakovleva, O. (2017). Initial education stage as the determinant of future translators' further academic success. Science and Education, 12, 5-10. https://doi.org/10.24195/2414-4665-2017-12-1

Scott, C. L. (2016). The Futures of Learning 2: What kind of learning for the 21st century? Paris: UNESCO Education Research and Foresight [ERF Working Papers Series, No. 14]. Retrieved January 27, 2019, from https://unesdoc.unesco.org/ark:/48223/pf0000242996

Tarnopolsky, O. B. (2018). Principled pragmatism, or well-grounded eclecticism: a new paradigm in teaching English as a foreign language at Ukrainian tertiary schools. Advanced Education, 10, 5-11. https://doi. org/10.20535/2410-8286.133270

Trotsko, A. V. \& Korotkova Y. M. (2018). Using information and communication technologies in the process of teaching foreign languages: the experience of Ukraine and Greece. Information Technologies and Learning Tools, 6 (68), 168-180. https://doi.org/10.33407/itlt.v68i6.2340

Wagner, T. (2010). The Global Achievement Gap. Cambridge: Mass., Harvard University, Graduate School of Education.

Zinukova, N. (2018). Metody`chna sy`stema navchannya studentiv magistratury` usnogo perekladu u zovnishn`oekonomichnij sferi (na materiali anglijs`koyi ta ukrayins `koy [Methodological System of Training Interpreting in Foreign Economic Field to Masters (English and Ukrainian)]. Doctoral dissertation, Kyiv, Ukraine. 


\section{Appendix 1}

\section{Interactive exercises}

Example 1. Lecture-workshop "Intonation modification: topical issues".

Objective: to improve the students' knowledge regarding the intonation modification in English and Ukrainian (semantics conveying, semantics of prosodic means); to stimulate their phonological abilities.

Process. The students were acquainted with modification patterns of intonation while conveying various semantics in English and Ukrainian; the intonation specificity depending on different communicative types of sentences. They were given examples demonstrating the alteration of Ukrainian and English melody, loudness and tempo characteristics. The future translators discussed the stated fact that the intonation of a communicative type of a sentence is closely connected with the attitudinal meaning expressed by the speaker in a speech act; compared the intonation of the Ukrainian and English speakers. Among the most widespread attitudinal meanings, they singled out these ones: a request/an order, a greeting/parting, doubt/a question, etc.

Example 2. Lecture-polylogue "Mechanisms of prosodic models correlation with various spheres of speech semantics".

Objective: to familiarise the future translators with the mechanisms of prosodic models correlation with various spheres of speech semantics within the two languages under study: English and Ukrainian; to motivate their cognitive comprehension of the designated issue by means of the heuristic method.

Process. The future English-language translators were invited to discuss the key points, as follows: (1) most communicative types of sentences demonstrate interaction with the prosodic markers of attitudes that correlate semantically with a certain communicative type; (2) attitudes are divided into two classes which differ according to presence / absence of prosodic constructions of "their own"; (3) prosodic actualisation of attitudinal complexes. The content of the lecture material provided for the students' awareness of the correlation mechanisms between prosody and communicative types. The format of the lecture made it possible to increase the students' attention to the problems raised, to stimulate the cognitive listening of their teacher and groupmates.

Example 3. Lecture "Students' self-guided work" (the core components and essence of the self-guided work performed by the future English-language translators in the sphere of interpretation were specified).

Objective: to familiarise the future translators with the contents of their self-guided work; to teach them to work independently under conditions simulating the professional ones.

Process. The students were asked to survey referential and scientific literature concerning the contents of the academic selfguided work. In class, they discussed the phonological phenomena like polysemy and synonymy of prosodic patterns. The future philologists-translators drove at the conclusion that prosody polysemy is actualised in two ways - meaning and function, polyfunctionality being reflected in prosodic functions mutual interaction (attitudinal, logical, semantic, communicative, syntagmatic delimitation, syntagmatic unification). At the end of each class, the students got an assignment to elaborate recommendations concerning the mechanisms of prosodic models correlation with various spheres of speech semantics: English vs Ukrainian.

Example 4. Seminar-panel discussion "Do it yourself".

Objective: to teach students to process academic material independently (without anybody's help) and decide which means to use while fulfilling professional tasks.

Process. The students were offered to represent their recommendations. Each student expressed his /her ideas related to prosody functions and their interaction, substantiated them and gave propositions concerning contrasted phonological phenomena in the framework of the English $\leftrightarrow$ Ukrainian interpretation.

*Thereafter the students confirmed a set of universal recommendations for further use. "Copyrighted" proposals to process audio and video texts in terms of decoding the semantics of the English and Ukrainian intonation depending on interlocutors' gender, social status, their emotional state, quality of sounding (presence / absence of noises, disconnection, communications interference, etc.) turned out to be substantive.

Interaction of the academic disciplines ("Major Foreign Language", "Minor Foreign Language", "Theory and Practice of Translation") facilitated students' practical training in analytical interpretation assignments.

The would-be English-language translators fulfilled exercises at different linguistic levels, before doing assignments covering texts of different functional styles.

Example 5. Exercise "Acting Art".

Objective: to teach the future translators / interpreters to find out phonostylistic correlates between literary text composition, style, vocabulary and grammar; to represent authentic texts correctly from phonetic point of view, taking into consideration performers' emotional and attitudinal implementation or emotionally-neutral "message".

Process. The students fulfilled pre-text assignments: studied abstracts from authentic English (the novel Sense and Sensibility by Jane Austen, the novel Gone With the Wind by Margaret Mitchell, the play Pygmalion by George Bernard Shaw) and Ukrainian (I. Котляревський «Наталка-Полтавка», М. Коцюбинський «Тіні забутих предків», М. Хвильовий «Романтика») artistic works, identified stylistic devices, expressive means and commented upon them. Then the students listened to audio texts (or viewed video versions) of the proposed literary works. After that they were to correlate the semantics of the stylistic devices and expressive means with the intonation of the main characters, to comment on the denotative and connotative semantics of the main characters' intonation and articulation particularities (of certain sounds / syllables), to imitate phonetic phonopassages of certain audio / video pieces. The post-listening assignments presupposed the sounding of extracts in accordance with emotionally neutral and emotionalattitudinal intonation models (one group). The other group of students were to listen to the dramatised literary works, to decipher emotional intention of the "actors / actresses" and to substantiate their opinion. The groups swapped their roles afterwards.

*Before dealing with authentic texts representing the functional style of opinion journalism, the future translators were to watch TV shows with the participation of prominent public and political figures and to reveal the style markers of their speech. 
Example 6. Exercise "Guess who the politician is".

Objective: to teach the future interpreters to detect the linguistic markers of the opinion journalism English / Ukrainian functional style; to identify emotionally marked phonetic speech units, to intone them as well as to reproduce the semantics of the English / Ukrainian interlocutors' intonation patterns in the target language.

Process. The students were to intone certain utterances, to analyse the intonation semantics of the extracts under study and to read them according to the patterns. Thereafter the future translators / interpreters sounded further extracts according to the set patterns. "The students - television viewers" were to detect if the represented texts matched the set patterns.

Example 7. A complex exercise "Phono-expert" (phonological level).

Objective: to motivate the future translators/interpreters to pronounce correctly separate English sounds / words / sentences / phonopassages, taking into consideration a functional style of the text and a form of prosody functions interaction.

Process. The future translators analysed intonation of the proposed text (timber, loudness, span, rate, pausation, accentuation specificity, rhythm, terminal tones, scale; paralinguistic characteristics) in terms of prosody functions interaction. After that, they were to discuss phonetic phenomena (assimilation, accommodation, reduction, elision, voicing / devoicing of consonants, etc.); to represent phonetical reading of the proposed texts according to the forms of prosody functions interaction: neutralisation, domination, equality and subordination.

In order to compare / contrast phonetic phenomena the students fulfilled a similar assignment involving texts in Ukrainian. The designated exercise facilitated their further training in sight interpretation during the experimental study.

\section{Appendix 2}

\section{Perception and production exercises}

Example 1. Exercise "Translator-scientist"

Objective: to form students' skills in cognitive listening of information (referred to diverse branches) in English and Ukrainian involving further subjective-attitudinal reproduction of its content.

Process. It was suggested that the students should listen to audio recording (in English and Ukrainian) of polylogues among conference participators concerning topical issues of a branch; identify the main idea, the general content of the dialogue / polylogue; find out the interlocutors' communicative intention. The students continued the dialogue with the conference participator(s) (group mate(s)) in the language of the conference according to the moral and ethical norms of the discourse. The correctness of the detailed understanding of the audio dialogue content alongside with the decoding of the interlocutors' intention facilitated its constructive continuation.

Example 2. Exercise "How should one achieve success in business at the international level?"

Objective: to form skills and abilities to adequately comprehend audio information which contains jamming (noise, disconnection, loud discussions of outsiders, interfering, etc.) in English / Ukrainian with further prediction of the discourse deployment.

Process. The students were to listen to authentic English / Ukrainian telephone conversations (containing obstacles); to detect the interlocutors' communicative intention. After that, the students discussed a strategy of cooperation with overseas colleagues in authentic language. It should be noted that the future translators interpreted the "damaged" phone conversation with enthusiasm and commented on the interlocutors' communicative intention. Their strategic and tactical versions of further cooperation with partners were suitable and substantive.

\section{Appendix 3}

Indicators of the professional competency of the future English-language translators in the field of interpretation

- phonological - students' awareness of the English and Ukrainian phonetic systems; their abilities to pronounce correctly linguistic units of segmental and suprasegmental levels according to the rules stipulating the use of different kinds of stress; to fix certain sounds, words, phrases and sentences in graphic form by means of the English and Ukrainian languages; to transcribe linguistic units; to decipher prosody patterns responsible for attitudinal and emotive functions; to differentiate prosody functions interaction while dealing with audio texts;

- audial - students' awareness of psycholinguistic regularities of generation and perception of the English and Ukrainian oral text / discourse; their abilities to aurally understand the main idea, the general meaning and details of multi-genre English material (debates, official reports, discussions, (non)-official negotiations, telephone conversations, radio- and TV programs, etc.), interlocutor's communicative intention by prosody as well as to keep the perceived information in the random access memory;

- oral transfer indicator - awareness of the psycholinguistic features of the process of the English-Ukrainian and UkrainianEnglish interpretation (consecutive interpretation) and auxiliary means of encoding information; bilingual skills to quickly switch from English into Ukrainian and from Ukrainian into English (to switch between them); the ability to synchronously perceive the oral text (English, Ukrainian) text and reproduce the text orally in the target language (English, Ukrainian) using the system of interpreter's notes. 